Hamilton observations of September 12, 13, and 14, that perihelion should occur at igro April 18.63 G.M.T., and that the nearest approach to the earth should take place on 1910 May ig at a distance of about o-14, i.e. about $13,000,000$ miles. Further, he points out that on May r8.14d. (G.M.T.) the earth and comet will be in heliocentric conjunction in longitude, the longitude being $236^{\circ} 48^{\prime}$; the heliocentric latitude of the comet will then be $-7^{\prime}$, so that, according to the present elements, no actual transit of the comet over the sun's disc will occur, but a slight change in the elements might produce one. "At any rate," he says, " it seems highly probable that we shall on May i 8 be inside the tail."

In a communication to the Times (October 25), Prof. Newall announces that he observed the comet, visually, with the 25-inch refractor, power 214 , on October $2 \mathrm{r}$. The magnitude was about 14.0 or 14.5 , and the faint nebulous patch had neither stellar nucleus nor definite borders; the diameter was estimated as 10 or 12 seconds of arc.

At the previous apparations, in 1759 and 1835 , the comet was first seen 77 and 102 days, respectively, before peri helion; Prof. Newall's observation was made about i 80 days before the calculated perihelion passage of 19 10, but he points out that this does not necessarily mean that the comet is so much brighter at the present apparition, for he would probably not have detected it had he not known its exact position as indicated by the previous photographic observations.

Quantitative Measures of the Oxygen Bands in the Srectrum of Mars.--In Bulletin No. 4I of the Lowell Observatory Prof. Very describes the methods by which he measured the relative strength of the $B$, oxygen, band in the spectrum of Mars, and discusses the results in their relation to the presence of, and quantity of, oxygen in the planet's atmosphere.

As Prof. Very points out, the $B$ band is normally so intense, by the absorption in the earth's atmosphere, that only by a method capable of the minutest accuracy could it be expected that any slight extra intensification, due to the Martian atmosphere, would become measurable. He claims that, over a long series of measures, his improved spectral-band comparator is capable of measuring this added interisification. Briefly, although a visual examination shows no increase of intensity of $B$ in passing from the spectrum of the moon to that of Mars, the comparator measures are surprisingly concordant in showing a positive value, in favour of Mars, several times greater than the probable error; $\mathbf{B}$, in the spectrum of the planet, is I $_{5}$ per cent. stronger than in the lunar spectrum, and the probable error is I. 8 per cent. There is, as would be expected, a considerable variation among the individual measures, but no contradictory results.

Stars having Peculiar Spectra: New Variable Stars. - Harvard College Observatory Circular, No: I43, contains a list of seven stars exhibiting peculiar spectra, and twentyeight stars shown to be variable. For each star the position, for 1900.0 , is given, and the class of spectrum indicated, whilst a series of notes summarises the observations. Some of the variables show a long range of magnitude, in one case amounting to 5.0

Circular No. $15 \mathrm{I}$ is a similar publication announcing the discovery of twenty new variable stars in the Harvard map No. 49. It also describes a star in Taurus, at

$$
\text { R.A. }=5 \text { h. } 43 \mathrm{~m} \text {. I2s., dec. }=+19^{\circ} 2 \cdot \mathrm{o}^{\prime} \text {, }
$$

which varies more than five magnitudes, and exhibits a light-curve of the rare $\mathrm{R}$ Coronæ Borealis type. Long periods of normal brightness are followed by sudden diminutions over a wide range, the normal brightness being 10.2 and the minimum fainter than 15.5 .

The Natal Government Observatory.-Mr. Nevill's report for the year 1908 deals chiefly with the meteorological observations, which, with the time service, form the chief work of the observatory, but it is noted that the large equatorial telescope was overhauled and repaired, and some observations were made with it by . Mr. Hodgson. Among these was a new series of lunar photographs, for the determination of the real libration, and some sketches of the surface configurations of Mars, Jupiter, and Saturn. No. 2087 , VOL. $8 I]$
FIRST MAGNETIC RESULTS OBTAINED ON THE "CARNEGIE" IN THE NORTH ATLANTIC.

THE non-magnetic yacht the Carnegie, engaged in a magnetic survey of the oceans under the direction of the Department of Research in Terrestrial Magnetism of the Carnegie Institution of Washington, left Brooklyn, New York, on her first cruise, August 2I, and proceeded direct to Gardiner's Bay, Long Island. Here several complete swings of the vessel were made with both helms in order to test the instruments, train the observers, and, above all, to determine whether actual non-magnetic conditions had been secured at the various positions of the instruments. These tests resulted most satisfactorily, not only proving the absence of deviations in the three magnetic elements (declination, dip, and intensity), within the errors of observation, at all observation positions, but also showing that with the instruments installed and the methods of observation employed a high degree of accuracy can be obtained.

Summary of Swings at Gardiner's Bay, Long Island, New York, August $3 \mathbf{I}$ to September 2, 1909.

\begin{tabular}{|c|c|c|c|c|c|}
\hline \multirow{3}{*}{ Ship's head } & \multicolumn{2}{|c|}{ West declination } & \multirow{2}{*}{$\frac{\text { Dip }}{\text { North }}$} & \multicolumn{2}{|c|}{$\begin{array}{c}\text { Horizon'al intensity in } \\
\text { C.G.S. units }\end{array}$} \\
\hline & M.C. & Deflector & & L.C.D.C. & Deflector \\
\hline & Position A & Position C & Position B & Position B & Position C \\
\hline N. & II 4 I & $I I^{\circ} 4 I$ & $72^{\circ} \cdot 02$ & 0.1823 & 0.1830 \\
\hline N.E. & I I 39 & I I 52 & $72 \cdot 12$ & 0.1823 & 0.1824 \\
\hline E. & I I 45 & I I 48 & 72.11 & 0.1823 & $0: 1830$ \\
\hline S.E. & II 39 & I I 29 & $72 \cdot 11$ & 0.1826 & 0.1824 \\
\hline S. & 1134 & $11 \cdot 4 \mathrm{I}$ & $72 \cdot 09$ & 0.1825 & 0.1831 \\
\hline S. W. & $11 \cdot 33$ & I I 28 & 7204 & 0.1824 & 0.1827 \\
\hline W. & $11 \cdot 32$ & II:40 & 72.08 & 0.1822 & 0.1823 \\
\hline N.W. & II 46 & I I 42 & $72 \cdot 18$ & 0.1823 & 0.1822 \\
\hline Mean $\ldots$ & II'39 & II 40 & $72 \cdot 09$ & 0.1824 & 0.1826 \\
\hline
\end{tabular}

Only one who has had experience both in the observations and reductions of magnetic elements determined at sea can appreciate the full significance of these results and can realise the advance made.

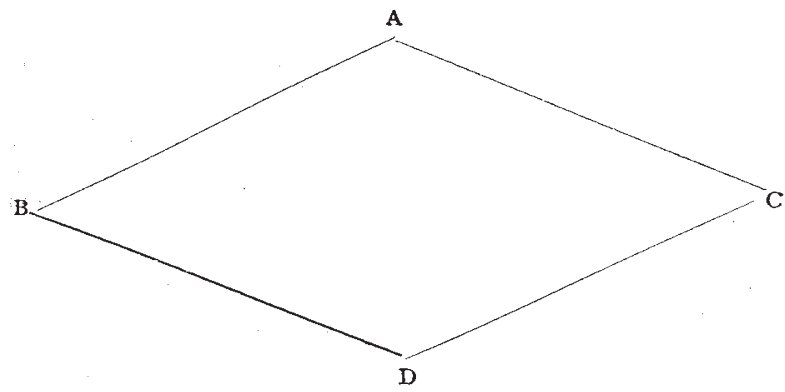

The above diagram will assist in the interpretation of the figures given in the above table, and at the same time make clear the general arrangements of the various instruments and the methods used. Consider the plane ABCD to be a vertical section through the four instrument positions and the fore and aft line of the vessel. Position A is on the bridge above the deck or chart-house, $B$ is in the forward observatory, $\mathrm{C}$ in the after observatory, and $D$ at the middle point of the chart-house, vertically below $\mathrm{A}$. The sides of the parallelogram are about $I_{3} \frac{1}{2}$ feet

At $\mathrm{A}$ is mounted the standard compass, one of a new type invented and constructed by the Department of Terrestrial Magnetism, and called the "marine collimating compass"; it will be found described in the March (I909) issue of the journal Terrestrial Magnetism. The basis of 
the instrument is a Ritchie 8-inch liquid compass with the card, however, removed, and an optical collimating system with scale introduced, enabling the observer to note the arc of motion of the magnet system while sighting on the sun or star, hence knowing precisely to what part of the are the stellar azimuth applies. In all forms of compass azimuth circles hitherto used, the magnetic azimuth of the celestial body must be taken from whatever point the card in its oscillations to and fro has momentarily reached. In brief, practically the same method of observations can now be used at sea as on land, where the magnetometer circle would be set to some convenient point on the magnet scale and then scale readings taken of the positions of the magnet during the interval of observations. The angle is next determined between the circle setting and some mark, or the true meridian, and the declination is finally deduced. Similarly with the marine collimator compass. The angle (say, middle of scale) between the magnet and some celestial body, as the sun, is read with a pocket sextant to the nearest minute of arc at a given time, and then scale: readings of magnet and of watch are taken. With the aid of the time readings, the motion of the sun during the interval of observation is taken into account, and the true azimuths determined, whereas the scale readings give the varying positions of the magnet system.

With this instrument, therefore, one is almost entirely independent of the yawing and rolling of the ship, making it possible still to get satisfactory results when with all other azimuth circle devices hitherto used at sea observations would be wholly impossible, or at least very uncertain.

In five to ten minutes a value of the magnetic declination is now obtained possessing an accuracy attainable with previous instruments only by most careful observation and by laborious repetitions extending over a half-hour or more to eliminate the motion of the card. Thus not only has the accuracy of declinations at sea been increased, but, what is equally important, the time has been reduced and the possibility of getting useful results in all linds of seas greatly extended.

Furthermore, sufficient attention has not always been paid in previous ocean magnetic work to a proper control of constants. Thus, e.g., with the compass azimuth circles, as usually. constructed, there are movable parts subject to wear, such as the axes of mirrors or of prisms and of the azimuth circle on the bowl. The wearing of these parts may easily bring about the same effect as though the compass were not mounted in the fore and aft line, i.e. introduce a quantity $\mathrm{A}$ not due necessarily to the ship s masnetism, but to instrumental error, which is likely to vary with extent of use of azimuth device. To control such errors, all instruments were invariably dismounted in the case of the vessel (the Galilee) employed in the Yacific Ocean work, whenever a port was reached, and corresponding observations made between land and ship instruments. With the present instrument, there being no such wearing paits, there will not be the source of error described.

It may also be pointed out that the effect of drag of magnet system moving in the liquid during changes of the ship's head is overcome in the present instrument, as well as in the one mounted at $\mathrm{C}$. for the method of observation involves turning the compass bowl opposite to the ship's riction.

At $B$ is the gimbal stand for mounting an L.C. dip circle, as modified for the Galilee work, with which the dip is determined absolutely (i.e. in all positions of circle and needle, inclusive of reversal of polarity by an electric coil) with two regular dip needles and again by the method of deflections, and total intensity is obtained using two deflecting distances.

At $\mathrm{C}$ is a Ritchie liquid compass provided with an improved azimuth circle and a deflecting attachment, both designed and made by the Department of Terrestrial Magnetism. With this instrument declinations are obtained, and also the horizontal intensity of the earth's magnetic force, by the method of defections independently with two deflecting magnets, the masnetic moments of which are controlled from time to time by shore observations whenever the vessel is in port, and using two deflecting distances. In these deffection observations the vawing of the ship, or the changes in the lubber-line from which the deflection angles are counted, is controlled by the recorder

No. 2087 , VOI. 8I] stationed at $\mathcal{D}$, who reads the ship's head by a spare Thomson dry compass. The same kind of deflecting device by which the deflecting magnet is brought at right angles to the axis of the deflected card, thus admitting of the simple sine-computation formula, is likewise attached to the marine collimating compass at $\mathrm{A}$. In the latter case the angle between deflected magnetic system and the sun (or true meridian) is read with a pocket sextant, thus making one entirely independent of the yawing of the ship.

The declinations obtained at $\mathrm{C}$ are intended chiefly as some control against any gross blunders which may be made at $\mathrm{A}$; for a fairly smooth sea they compare favourably with those got at $A$, but in rough seas the great superiority of the A results is very evident.

In brief, then, the scheme of observations, whenever fully carried out, will yield the following determinations in about one hour's time by independent observers, with different instruments, and at different positions on the vessel :-

At A.-Declinations (also horizontal intensity when a celcstial body is long enough visible to permit of full sets of deflection observations).

At B.-Two values of dip by the regular absolute method, and two values of total intensity and of dip, using two deflecting distances.

The horizontal intensity is determined by computation from the dip and the total intensity.

At C.- Two values of horizontal intensity independently with two magnets, and using each time two deflecting distances; also, whenever possible, magnetic declinations $\mathrm{D}$, as above described, is simply accessory to $\mathrm{C}$, and does not furnish any direct result.

It is thus seen that an effective control is obtained for each magnetic element, and it is for this purpose a great gain indeed that it is now possible to compare at once the values of horizontal intensity, for example, got at $\mathrm{B}$ and $\mathrm{C}$ without first waiting until the deviations are well determined, as has hitherto been the case in all previous vessels engaged in magnetic work-even on the Galilee, which, before the Carnegie, had the smallest deviations of any ship.

Besides the great improvement resulting from having a non-magnetic vessel, and from the perfection of the instruments themselves, the conditions and opportunities for observing have also been materially bettered on the Carnegie. Thus the instruments at $\mathrm{B}$ and $\mathrm{C}$ are under shelter, being mounted in observatories with revolvirg domes and movable slides, permitting of both magnetic and astronomical observations, with full protection to the observer and instrument from wind and weather.

Outstanding Difficulties.-These are chiefly due to meteorological conditions and the state of the sea. Thus in the absence of sun or star no magnetic declinations can be obtained, though dip and intensities may be got even in a pouring rain, because of the introduction of the sheltering observatories. It is hoped that some instrument based on the gyroscope compass may be soon perfected having the desired accuracy, with the aid of which the direction of the magnetic needle may be referred to an invariable plane to be controlled whenever a celestial body becomes visible.

Were one to wait for a calm or a fairly smooth sea it would occur quite frequently that no magnetic results would be forthcoming. In fact, on the entire recent October passage of the Carnegie from St. John's, Newfoundland, to Falmouth, England, there was not a single day which would fall in the usual category of favourable days of observation, but, instead, on nearly every day there was a gale, the sea was rough, the vessel yawed through an angle of $10^{\circ}$ or more, and rolled through an arc of $20^{\circ}$ to $30^{\circ}$ and more, and yet observations were secured on every day except one. That utilisable magnetic results have still resulted under such very adverse conditions is due to the perfection of the instruments, the cutting down of time required for observations to get a desired degree of accuracy, thus reducing to a minimum the condition of steadiness of ship, and, of course, to the skill of the observers. Still further improvements are being striven for with regard to independence of steadiness of ship.

It is thus scen that while the endeavour is steadfastly held in mind to measure the magnetic elements at sea 
with every possible precision, the improvements made, and yet to be made, are along the line of reduction in time required to achieve the desired result-in other words, towards simplicity. With proper instrumental means and methods it need not require any more time to make accurate observations than to get indifferent results with instruments not adapted to the conditions to be met.

As a proof of this is given below the table of results of the work on board the Carnegie from September I to October 18 , or in about six weeks' time. After the tests in Gardiner's Bay referred to above, the vessel proceeded, under the command of Wm. J. Peters, to New London, Connecticut, to have some slight alterations made. She left this port on September II bound for St. John's, arriving there September 25 . Here the director rejoined her, having left the vessel in Long Island Sound to attend the meeting of the British Association at Winnipeg, Canada.

After the necessary shore observations, the Carnegie set sail from St. John's on October 2 direct for Falmouth, England, arriving there on October 14 , having had favourable winds. Owing to the lateness of the season the Hudson Bay cruise for this year had to be abandoned. vessel. The installation is in the charge of the chief engineer, Mr. D. F. Smith, who has had both theoretical and practical experience with gas engines. Mr. Carl Smith, an acknowledged gas-engine expert of the technological branch of the United States Geological Survey, is consulting expert in connection with this work. Should this type of engine be made a practical success for marine purposes, even though it be but for auxiliary uses, it will be a valuable achievement, being the most economical form of motor now employed.

The Magnetic Results.-In submitting now the magnetic results obtained to date, it should be stated that the com putation and revision of results goes on apace on board with the observational work, not only that possible errors may quickly be detected, but also that the results may be made known promptly. It is the intention, hereafter, to publish the results at intervals of about three months.

Accuracy of: Magnetic Results.-In general, the declinations given may be taken as correct within $0 \cdot 1^{\circ}$, and only in but a few instances, when the conditions of sea were unusually bad, will the error be $0 \cdot 2^{\circ}$; under favourable conditions the observation error in declination with the marine collimating compass for the mean result will be

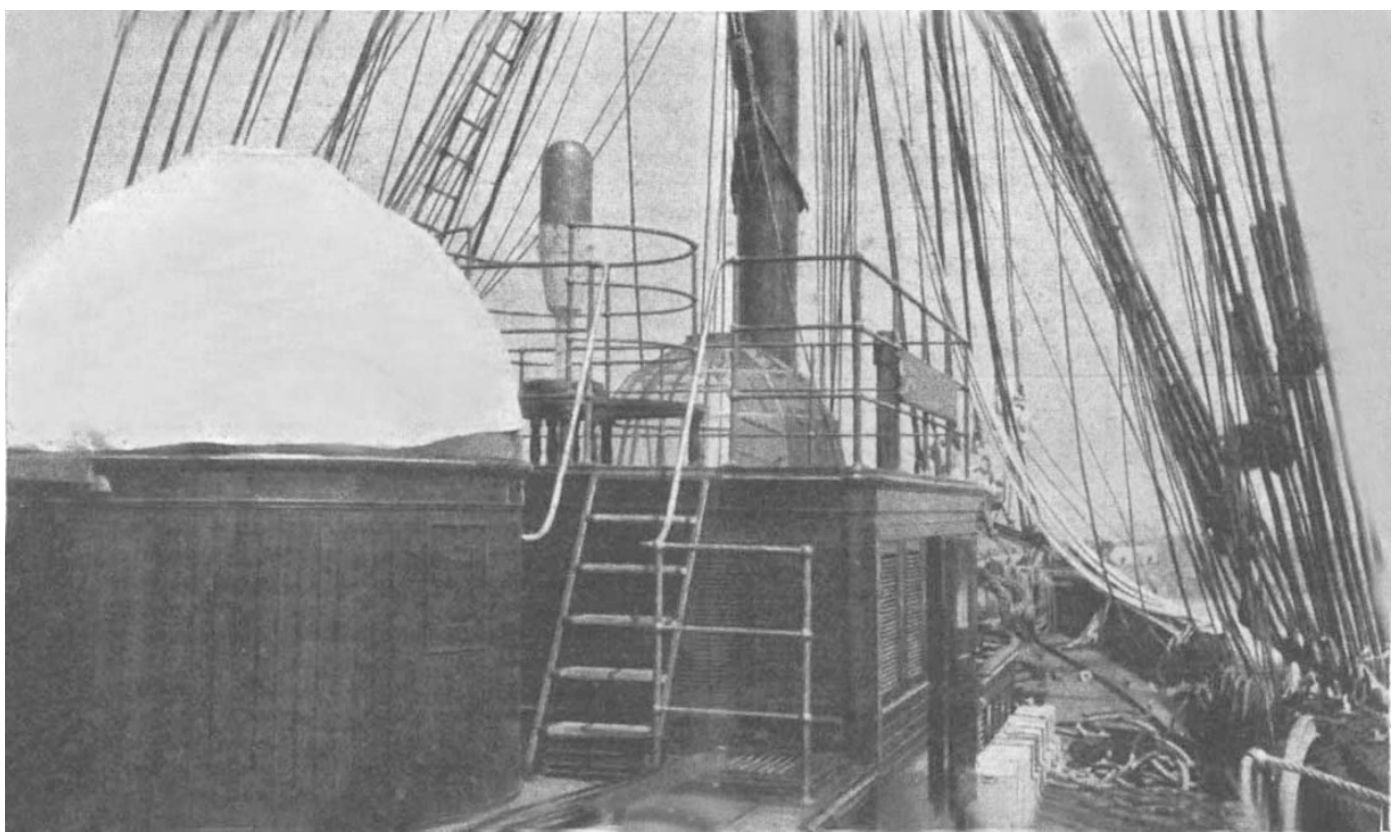

Deck view of the Carnegie, showing the chart hcuse with Marine Collimator (A in diagram) in the middle and the two observato ies. The forward one is uncovered, and inside it position B of the diagram, where the L.C. Dip Circle is mounted; inside the after observatory (the covered one) is mounted the Deflector and Compass (Position C).

After the completion of the harbour and shore observations at Falmouth, the Carnegie, continuing under the command of Mr. Peters, will proceed to Madeira, and will return early next year to New York via Bermuda, the director returning to Washington.

Personnel:-Besides the director of the department and the commander of the vessel, the scientific and navigation staff is composed as follows :-C. E. Littlefield, sailing master; J. P. Ault, E. Kidson, R. R. Tafel, observers; Dr. C. C. Craft, surgeon and observer; and D. F. Smith, chief engineer. The ship's personncl includes, furthermore, two watch officers, two cooks, eight seamen, and one mechanic.

Auxiliary Propulsion.- Of considerable interest in marine circles, aside from the magnetic work on board this vessel, are the experiments being made in the perfecting of a producer-gas engine for marine propulsion. Such a plantand an almost entirely non-magnetic one-is aboard the Carnegie, of 150 horse-power, sufficient to drive her at six knots' speed in calm weather. This engine has already proved a useful adjunct to the vessel's equipment, facilitating the entering and leaving of ports, and such tests as were made at Gardiner's Bay requiring swinging, of the NO. 2097 , VOL. 8I] about $\pm 0.05^{\circ}$ (see the Gardiner's Bay results). About the same statement as made for the declination applies to the dip. The horizontal intensities, as at present given, may be assumed correct within I unit in the third decimal for the severe conditions encountered on the greater part of the cruise thus far; for fairly good conditions of the sea the error need not be more than 5 in the fourth decimal, and may be made less, as shown by the Gardiner's Bay work.

In making these preliminary statements, it should be remarked that every possible source of error is consideredin other words, absolute accuracy, not relative accuracy, is meant. For example, when it is declared that, given fairly good conditions, it is possible to get the dip on board the Carnegie within $0.05^{\circ}$, i.e. within three minutes absolutely, this means more than may at first appear. Thus dip circles-especially ship dip circles-have instrumental corrections exceeding frequently the relative error of observation. Accordingly, the dip circle on the Carnegie has been compared, not only with various observatory dip circles, but also with an earth inductor at Washington, for the range of dip from $+88^{\circ}$ to $-60^{\circ}$. Further control will be had at the various ports of call during the progress of 
the work. This serves as an illustration of the care required and being taken, not only with this form of magnetic instrument, but with every instrument used aboard.

We have preferred to underestimate our absolute accuracy rather than to overestimate it. In any case, it may be said that the magnetic elements are now being obtained on the Carnegie with sufficient accuracy, not only for practical demands, but also for purely scientific ones.

Were we able to choose the time to observe and wait for fairly smooth sea, the magnetic elements could be determined at sea with an accuracy practically the same as in the determinations for land magnetic surveys.

Diurnal Variation Corrections.- No corrections for diurnal variation need, in general, be applied. The attempt is being made to get the magnetic elements at such times of the day when these corrections are small or are of the order of the error of observations. Thus, for example, the most favourable condition for the declination work is when the sun is low, i.e. early in the morning or late in the afternoon, and at these times the diurnal variation correttions are small and frequently of opposite sign. Should there be evidence of magnetic disturbance during the observations, or as may appear later from observatory records, the observations, if necessary, will be rejected.

Geographic Positions.-Equal care is bestowed upon the determination of the geographic positions of the points where the magrietic observations are made. The astronomical observations and computations arémade in duplicate, and at times in triplicate, by the observers, and thus the positions are effectively checked. Six well-tested chronometers are carried aboard. With the methods followed, it would appear that the errors in the final positions assigned will, in general, be less than three minutes of arc in latitude and in longitude.

Magnetic Results obtained on the "Carnegie," September I to October. I8, 1909, in the North Atlantic Ocean.

\begin{tabular}{|c|c|c|c|c|c|c|c|c|c|}
\hline \multirow{2}{*}{ No. } & \multirow{2}{*}{$\begin{array}{l}\dot{z} \\
\dot{g} \\
\stackrel{9}{\mid c}\end{array}$} & \multirow{2}{*}{ 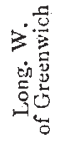 } & \multirow{2}{*}{ 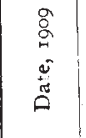 } & \multirow{2}{*}{ 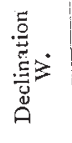 } & \multirow{2}{*}{$\begin{array}{l}z \\
a \\
a\end{array}$} & \multirow{2}{*}{ 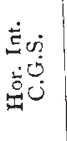 } & \multicolumn{3}{|c|}{$\begin{array}{l}\text { Corrections of } \\
\text { Variation Charts }\end{array}$} \\
\hline & & & & & & & British & U.S. & Ger. \\
\hline 2 & $4 x^{\circ} \cdot 1$ & $7^{2} \cdot 2$ & Sept. r & $\mathrm{TI}^{*} 4$ & $\begin{array}{l}7^{\circ} \cdot 1 \\
7^{2}\end{array}$ & $0^{\prime} 18_{3}$ & +0.4 & +0.5 & +02 \\
\hline 2 & & $7^{r^{*}}$ & & 123 & $72 \%$ & 0.182 & 0.6 & +0.3 & +0.6 \\
\hline 3 & $40^{\circ}$ & & 14 & $12: 9$ & & 0.85 & +0.8 & +09 & +07 \\
\hline $\begin{array}{l}4 \\
5\end{array}$ & $40^{\circ}$ & $\begin{array}{l}69.4 \\
68.4\end{array}$ & $x_{4}$ & 12.8 & $7 \times 7$ & $\begin{array}{l}0.185 \\
0.82\end{array}$ & +0.22 & +0.4 & +04 \\
\hline $\begin{array}{l}5 \\
6\end{array}$ & $\begin{array}{l}40.9 \\
40^{\circ} \mathrm{C}\end{array}$ & $\begin{array}{l}68.9 \\
68.4\end{array}$ & $\begin{array}{l}35 \\
16\end{array}$ & $\begin{array}{r}13.9 \\
74.4\end{array}$ & $70^{\circ} 9$ & $0^{0.182}$ & $\begin{array}{l}+0.8 \\
+0.8\end{array}$ & $\begin{array}{l}+0.4 \\
+0.3\end{array}$ & $\begin{array}{l}+0.7 \\
+0.6\end{array}$ \\
\hline${ }^{\prime}$ & 413 & & 17 & $\begin{array}{r}4.4 \\
16.2\end{array}$ & $7 \times 99$ & $0^{\circ} 181$ & +0.8 & & $\begin{array}{l}+0.0 \\
+0.0\end{array}$ \\
\hline 8 & $42^{\circ} \circ$ & $6 \mathrm{x}$ & 20 & $20^{\circ} 2$ & - & 0.177 & $+r \cdot x$ & +0.7 & +0.8 \\
\hline 9 & $42^{\circ}$ & & $2 \pi$ & $20: 8$ & - & 0.176 & & +0.6 & +06 \\
\hline & & $\begin{array}{l}60.8 \\
58.9\end{array}$ & $\begin{array}{l}21 \\
22\end{array}$ & $2 \mathrm{r}^{4} 4$ & $7^{2} \cdot 5$ & 0.173 & $\begin{array}{l}+144 \\
\end{array}$ & +0.9 & +0.4 \\
\hline I & 43. & & $\begin{array}{l}22 \\
23 \\
23\end{array}$ & 23.7 & 727 & 0.171 & $+1 \cdot 5$ & +0.7 & $+r_{3} 3$ \\
\hline 12 & 45 & $\begin{array}{l}537 \\
52 \cdot 6\end{array}$ & $\begin{array}{l}23 \\
25 \\
25\end{array}$ & - & $\begin{array}{l}727 \\
7\end{array}$ & $\begin{array}{l}0.169 \\
0.158\end{array}$ & = & E & - \\
\hline 13 & $\begin{array}{l}47 \\
47\end{array}$ & 527 & $\begin{array}{l}25 \\
28 ! \\
28\end{array}$ & - & 73.5 & $\begin{array}{l}0.158 \\
0.150\end{array}$ & -7 & - & - \\
\hline$=5$ & $\begin{array}{l}47.0 \\
47.8\end{array}$ & $5 r_{4}$ & Oct. $\begin{array}{r}28 \\
3\end{array}$ & $\begin{array}{l}29.75 \\
30^{4}\end{array}$ & $73^{-5}$ & 0.059 & $\begin{array}{r}0^{\circ} \circ \\
+0^{\circ} 2\end{array}$ & $\begin{array}{r}0.0 \\
-0.2\end{array}$ & $\begin{array}{r}0^{\circ} \circ \\
+0^{\circ} 0\end{array}$ \\
\hline $\begin{array}{l}15 \\
16\end{array}$ & 48.2 & $50^{\circ}$ & 3 & & 73.5 & 0.157 & - & - & - \\
\hline$x 7$ & 48.4 & $48 \%$ & $4 !$ & $3 T^{\top} \cdot 8$ & & & +0.4 & +0.3 & $+r \cdot 2$ \\
\hline $\begin{array}{l}18 \\
19\end{array}$ & $\begin{array}{l}4^{8} \\
4^{8}\end{array}$ & $\begin{array}{l}477 \\
46.5\end{array}$ & 4 & $\begin{array}{l}31.8 \\
31.8\end{array}$ & $73^{\circ} \mathrm{O}$ & $0.16 \mathrm{I}$ & $\begin{array}{l}+0^{\circ} 2 \\
-0.7\end{array}$ & $\begin{array}{l}+0^{\circ} \mathrm{r} \\
-0^{\circ} \cdot{ }^{2}\end{array}$ & $\begin{array}{l}+r^{\circ} \cdot \\
\end{array}$ \\
\hline $\begin{array}{l}19 \\
20\end{array}$ & $\begin{array}{l}40 \\
48\end{array}$ & $45^{\circ} 5$ & & $\begin{array}{ll}318 \\
33^{2}\end{array}$ & $72^{\circ} 5$ & $\cdot 16 \mathrm{r}$ & $\begin{array}{l}-0 . T \\
-0 . T\end{array}$ & -02 & $+r^{\circ} \mathbf{r}$ \\
\hline $2 \mathrm{I}$ & $49^{\circ} 6$ & 37.5 & $5 !$ & $3^{2} \mathrm{I}$ & 71.2 & $\begin{array}{l}.101 \\
0.168\end{array}$ & $-0 . x$ & -0.3 & $+\mathrm{r}^{\circ} 5$ \\
\hline 22 & 50.3 & $32 \cdot \mathrm{I}$ & $\dot{8}$ & $30 \% 2$ & 707 & $0^{\circ} 17^{1}$ & -0.4 & -0.4 & $-0_{4}$ \\
\hline 23 & 50 & 28.8 & 9 & $\begin{array}{r}290^{\circ} \\
26.6\end{array}$ & 二 & 二 & $\begin{array}{l}-0.7 \\
-0.6\end{array}$ & -0.8 & $\begin{array}{l}-07 \\
-0.8\end{array}$ \\
\hline $\begin{array}{l}2 \\
2\end{array}$ & $50^{\circ} \mathrm{t}$ & & $\begin{array}{l}\text { To } \\
\text { Io }\end{array}$ & $26^{\circ} 6$ & $\overline{60^{\circ} 2}$ & $-\overline{174}$ & -0.6 & -0.9 & -0.8 \\
\hline 26 & $50^{\circ}$ & $19^{\circ} 2$ & II & 24.5 & & ${ }^{0.174}$ & $-\overline{0.2}$ & $-\overline{0}^{\circ}$ & $\overrightarrow{-0^{\circ} 3}$ \\
\hline 2 & $50^{\circ} 3$ & $17^{\circ} 2$ & $\mathbf{I r}$ & 22.9 & 68.3 & 0.180 & -0.9 & -0.8 & -0.9 \\
\hline 28 & $49^{\circ}$ & II.9 & $x 2 !$ & $20^{\circ} 3$ & 67.4 & 0.185 & & -0 & -0.5 \\
\hline 20 & $49^{\circ}$ & 93 & 5 & 197 & & - & $+0^{\circ} 2$ & $+0^{\circ} x$ & +0.2 \\
\hline , & $49^{\circ}$ & 7.5 & 13 & I8.6 & $66^{\circ}$ & 0 & $\circ$ & $-0 . \tau$ & $-0^{0} I$ \\
\hline $\begin{array}{l}31 \\
32\end{array}$ & $\begin{array}{l}500^{\circ} \\
50^{\prime} 1\end{array}$ & $\begin{array}{l}5.0 \\
5 \%\end{array}$ & 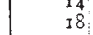 & $\begin{array}{l}17.5 \\
17.8\end{array}$ & $66 \%$ & 0.187 & $\begin{array}{l}+0 \\
+0.2\end{array}$ & $\begin{array}{r}-01 \\
+0.2\end{array}$ & $\begin{array}{l}-0.2 \\
+0.1\end{array}$ \\
\hline & & & & & & & & & \\
\hline
\end{tabular}

No. $x$ in Gardiner's Bay; No. 14 at St. John's, Newfoundland; No. 32 in Falmouth Bay.

1. Magnetic Storms and Northern Lights. - It so happened on board the Carnegie that no magnetic observations were in progress during the severe portions of the niagnetic storns of September 25 and Octoher $18-10$. No
Greenwich time signals could be obtained at St. John's from Heart's Content Greenwich time signals could be obtained at St. John's from Heart's Content nn the morning of September 25 on account of heavy earth currents evening of September $2 x$ in latitude $43^{\circ} \mathrm{N}$. and longitude $60^{\frac{1^{2}}{2}} \mathrm{~W}$. of Green wich. A glow of white light with occasional streamers extended upward about $10^{\circ}$ above the horizon from a low bank of cumulo-stratus clouds. The display was in the magnetic north. The evenings of September 22, 23, 24, and 25 were cloudy or foggy.

NO. 2087 , VOL. 81]
Corrections of the Present Magnetic Charts. The table requires no explanation other than is already given in the headings, with the exception of the last three columns, which exhibit the quantities to be added to or subtracted from the declinations scaled from the lines of equal magnetic declination ("variation of the compass"), first, as given by the British Admiralty chart, I907; next, by the United States Hydrographic Office for I9Io; and, lastly, by the Deutsche Seewarte for $1905 .^{\mathrm{I}}$ In all cases the values scaled from the charts have been referred to the present time with the aid of the secular variation corrections as given on the respective charts. It will be seen that, in the case of each chart, the corrections are usually less than $\mathrm{I}^{\circ}$, and, considering the miscellaneous data at the disposal of the makers of the charts and the uncertainty of the secular variation reductions, the general correctness of the charts is most gratifying.

However, one fact, revealed by the prevalence in sign of the quantities appears to be of sufficient practical importance to require attention. The data given in the table apply pretty closely to the tracks followed by the Transatlantic steamers between New York and England.

Along the portion from New York to a point somewhat beyond Sable Island the corrections for each chart are positive, amounting in the maximum to $\mathbf{I}_{2}^{\circ}$; they then change sign, with eastwardly progression, reaching a negative value of nearly $I^{\circ}$. In other words, for the track pursued by the Atlantic liners from England to a point off Sable Island, the present magnetic charts, in general, show too large westerly declination, whereas on the remainder of the route to New York the charts give too small westerly declination.

It can readily be seen what the effect of these systematic errors of the charts would be on the course of a vessel sailing from England to New York if, during the entire passage, no sun or stars were visible, as sometimes occurs so that the course of the vessel would have to be shaped entirely by the compass and the log. At the end of the 2000 miles of the great circle route the vessel, off Sable Island, would be about thirty miles too far north of her regular track, and if the set of the current were in the same direction the vessel would easily be exposed to shipwreck. From Sable Island to New York the effect of the chart errors, being reversed in sign to what they were before, would be in the opposite direction, i.e. the vessel would be put out of her true course in a southerly direction.

For a vessel going eastward the effects are just reversed; hence on the course from New York to Sable Island the tendency of the chart error would be to set the vessel to the northward, hence again towards the source of danger: thereafter the vessel would be set to the southward of her outlined course. So that, if proper allowance were not made, a captain would have his vessel turned off towards Sable Island or Cape Race, whether he came from the east or from the west.

It appears to be known to some captains, at least, that there. is some such systematic change which, judging from conversations had with them by one of the present writers (Bauer), during various Atlantic voyages, is ascribed by them to a systematic change in their ship deviations. Two captains have told him, independently of each other, that after their compasses had been carefully adjusted they have noticed bv repeated observation a systematic change in the deviations, which reversed in sign when Sable Island was passed. The effects would be opposite for the eastward and the westward cruises. The deviations referred to by these captains are the differences between chart values and those observed with their adjusted standard compasses; hence they are not pure deviations, but are the sums of ship deviation and chart error. The work of the Carnegie has now proved that the cause of the systematic change and reversal of ship deviations encountered by these painstaking captains was due, in part at least, to systematic errors in the variation charts.

The corrections for the chart of the lines of equal magnetic dip (British Admiralty Chart of 1907 and the Deutsche Seewarte of 1905) are generally less than $\frac{1}{2}{ }^{\prime}$, being sometimes plus and sometimes negative.

The lines of equal horizontal magnetic intensity as laid

1 The latest chart of the Deutsche Seewarte is not at present to hand. 
down on the British Admiralty Chart for 1907 are in error by amounts reaching 16 units in the third decimal C.G.S. and those of the Deutsche Seewarte for 1902 (the most recent chart not being available to us just now) require corrections running up to is units in the third decimal on the values obtained by the Carnegie. A part of this error is, of course, due to secular variation, but the major portion appears to be due to defective data. For both charts there are five negative corrections, amounting in the maximum to 4 units in the third decimal, four zero values and thirteen positive ones for the "B.A." chart, and two zero and fifteen positive corrections for the "Seewarte" chart. On the average for the Atlantic, from Long. Island to Falmouth, the chart values are too low by about $\mathrm{r} / 45^{\text {th }}$ part of the value of the force, even at times amounting to 10 per cent. to 20 per cent. In the Pacific Ocean the intensity charts gave, in general, too high values by about $1 / 25^{\text {th }}$ part.

Since the above was written the Carnegie has been swung in Falmouth Bay, observations of the three magnetic elements (declination, dip and horizontal intensity) being made on eight equidistant headings. The mean results of the entire swing are in excellent agreement with what would be deduced from Rüicker and Thorpe's magnetic charts of the British Isles applying secular variation corrections as deduced from the records of the Falmouth Magnetic Observatory. The declinations and dips agree within two or three minutes, and the horizontal intensity within $\mathrm{x} / 2$ oooth part. This again proves that there are no deviation corrections of whatever nature to be applied to the Carnegie results; also that the instrumental constants have been well determined. We have here also a satisfactory proof that if the distribution of magnetism is uniform, as appears to be the case here, the sea values, upon careful measurement, will be found in agreement with the shore values.

L. A. Bauer.

W. J. Peters.

\section{THE ANALYSIS OF SOUNDS USED IN SPEECH.}

THE characteristics of the simpler sounds which form the elements of speech have been studied by many physicists. At first, attempts were made to reproduce the vowel sounds synthetically; Helmholtz achieved noticeable successes in this endeavour, but by themselves synthetical methods can never be quite satisfactory, since it is necessary to prove that the ear does not possess properties similar to those possessed by the eye; it is well known that two mixtures of light may produce identical effects on the eye, although the component waves may be quite different in the two cases.

Many attempts have been made to analyse complex sounds, but the results obtained up to the present have not been quite conclusive. Dr. Erskine-Murray used a thin membrane stretched slackly over the small end of a conical tube; a light mirror was adjusted so that it was rocked to and fro by the motion of the membrane, and a beam of light was reflected from this on to a revolving mirror and thence on to a screen. Such an arrangement is very sensitive for sounds of low pitch, but it is mechanically unsuitable for analysing. sounds of high frequency. Hermann, McKendrick, and Bevier have attacked the same problems by analysing phonograph records, and have obtained much useful information; but there. is small reason to suppose that a phonograph record, however good it may be, affords an exact equivalent to human speech.

For some time past Mr. G. Bowron, of 57 Edgware Rond, has devoted attention to the construction of an oscillograph which projects on a screen a curve representing the sounds produced by a gramophone; a brief notice of this oscillograph was given in NATURE of May $2 \mathrm{I}, 1908$ (vol. lxxviii., p. 69). The curves obtained are very instructive, and they appear to possess as much detail as those obtained by the elaborate method of Prof. McKendrick; but the problem of the analysis of the sounds used in speech can scarcely be solved in this way.

The best curves representing vowel sounds have been No. 2087, VOL. SI obtained by Mr. Duddell; some of these are published in the Journal of the Institution of Electrical Engineers (vol. xxxix., No. 186, 1907, pp. 545-6). They were obtained by speaking into a " solid-back" telephone transmitter, and transmitting the periodic current obtained thereby through the high-frequency electrical oscillograph invented by Mr. Duddell. The regularity of these curves is very striking; a perfectly definite curve corresponds to each vowel sound, and with some practice it would be possible to decipher a telephone message by inspecting the curve which corresponds to the telephone current. It may be mentioned, in passing, that the analysis of the sounds which constitute, speech is now acquiring commercial importance in connection with the problem of telephone transmission.

Mr. Bowron has constructed an acoustic oscillograph intended to show the vibrations comprised in ordinary speech; but although this gives some interesting information, the curves obtained are not nearly so good as those obtained by Mr. Duddell. The arrangement used is somewhat like that due to Dr. Erskine-Murray, but the slack membrane is replaced by a ferrotype telephone diaphragm. In practice it is found that Mr. Bowron's oscillograph does not give good curves for sounds of low pitch; this is due to the fairly high frequency of the natural vibrations of the diaphragm. It has been pointed out by $\mathrm{Mr}$. $\mathrm{A}_{4}$ Campbell (Jour. Inst. Elec. Engineers, vol. xxxix., No. I 86, p. 533) that even a microphone transmitter has certain definite free periods, and that sounds of the corresponding pitches are greatly reinforced. Mr. Campbell's experiments in proof of this are worthy of mention here. A solid-back microphone is put in circuit with a battery of 6 volts or 8 volts and the primary circuit of a fair-sized spark coil. The secondary of this coil is connected to a reflecting electrostatic voltmeter reading up to ro volts. The deflections of the voltmeter afford a sensitive indication of sounds received by the microphone. If the nearly pure note of a stopped organ-pipe be sounded, a deflection of the voltmeter is produced, and if the pitch of the note be gradually raised the spot of light rushes off the srale when the note attains certain definite frequencies. This arrangement might be used with advantage in cases where measurements of the intensities of sounds are required.

There can be little doubt that much remains to be done in connection with the analvsis of the sounds used in speech. Thus the curve obtained by Mr. Duddell for the oo sound in "coo" scarcely differs from a sine-wave curve; a slight alteration of the mouth introduced the octave of the fundamental vibration. According to the accepted theory of vowel sounds, each vowel is distinguished by the reinforcement of those partials which lie near to certain definite pitches. The question could be answered definitely if we possessed a diaphragn which would vibrate indifferently for all pitches; and since the drum of the ear does this, it may be hoped that we may be able to realise the conditions necessary to the. solution of the problem.

EDWIN EDSER.

\section{HEAT TRANSMISSION.}

A PAPER on heat transmission was read by Prof. W. E. Dalby before the Institution of Mechanical Engineers on Friday, October 15. The object of the research was to place before the members a general view of the work which has been done relating to the transmission of heat across boiler-heating surfaces, and in carrying this out more than 500 papers have been read and abstracts of the more important prepared.

In a furnace heat is transmitted by three methods simultaneously, viz. radiation, convection, and conduction. It is extremely difficult to analyse the results of experiments, so that the heat transmitted by each of these methods may be stated separately. Formulæ of simple type have been devised to express the results of definite sets of experiments; the application of such formulæ should be strictly limited to cases in which similar conditions prevail and fall within the range of the original experiments.

In discussing radiation, the author gives Stefan's law. 